\title{
Prevalence, risk factors, and health-related quality of life of osteoporosis in patients with COPD at a community hospital in Taiwan
}

This article was published in the following Dove Press journal:

International Journal of COPD

29 July 2015

Number of times this article has been viewed

\author{
Chun-Wei Lin ${ }^{1,2}$ \\ Yih-Yuan Chen ${ }^{3}$ \\ Yi-Jen Chen ${ }^{1,4}$ \\ Chi-Yen Liang' \\ Ming-Shian Lin ${ }^{1,4}$ \\ Wei Chen ${ }^{1,5,6}$
}

'Division of Pulmonary and Critical Care Medicine, Chia-Yi Christian Hospital, Chia-Yim, ${ }^{2}$ Division of Chest, Division of Pulmonary Medicine, Kuang Tien General Hospital, Taichung, ${ }^{3}$ Department of Internal Medicine, Chia-Yi Christian Hospital, ${ }^{4}$ Department of Respiratory Care, Chang Gung University of Science and Technology, Chiayi, ${ }^{5}$ College of Nursing, Dayeh University, ${ }^{6}$ Department of Respiratory Therapy, China Medical University, Taichung, Taiwan
Correspondence: Ming-Shian Lin;

Wei Chen

Department of Internal Medicine;

Division of Pulmonary and Critical Care Medicine, Chia-Yi Christian Hospital,

539 Jhongsiao Road, Chiayi 600, Taiwan

$\mathrm{Tel}+8865276504$ I

Fax +886527745I I

Email 02456@cych.org.tw;

peteralfa2004@yahoo.com.tw
Background: Data regarding osteoporosis in COPD patients in Taiwan remain limited. The primary end point of this study was to evaluate the prevalence and risk factors of osteoporosis in COPD patients in Taiwan. The secondary end point was to examine the association between osteoporosis and health-related quality of life (HRQL) in COPD patients.

Materials and methods: This prospective cross-sectional study enrolled 125 COPD patients (mean age 73.6 years, forced expiratory volume in 1 second $\left[\mathrm{FEV}_{1}\right] 1.19 \pm 0.43 \mathrm{~L}$ ) who had bone mineral-density measurements performed consecutively. Demographic data, lung function, and HRQL including modified Medical Research Council dyspnea scale, St George's Respiratory Questionnaire, oxygen-cost diagram, Center for Epidemiologic Studies - depression scale, and COPD Assessment Test scores were recorded.

Results: A total of $50(40 \%)$ participants were diagnosed as having osteoporosis. In a multivariate logistic regression model including age, smoking amount (pack-year), body mass index (BMI), and $\mathrm{FEV}_{1}$, only BMI (odds ratio 0.824, 95\% confidence interval 0.73-0.93; $P=0.002$ ) and $\mathrm{FEV}_{1}$ (odds ratio $0.360,95 \%$ confidence interval $0.13-0.98 ; P=0.046$ ) were negatively associated with an increased risk of osteoporosis in COPD patients. In addition, COPD patients with osteoporosis had significantly higher modified Medical Research Council dyspnea scale scores $(1.7 \pm 0.8$ vs $1.4 \pm 0.8, P=0.046)$, St George's Respiratory Questionnaire scores (36.6 vs 28.0, $P=0.01$ ), and COPD Assessment Test scores (14.7 8 vs 11.5 \pm 7 , $P=0.019)$, and lower oxygen-cost diagram score $(4.8 \pm 1.8$ vs $5.4 \pm 1.6, P=0.045)$ than patients without osteoporosis.

Conclusion: The prevalence of osteoporosis in COPD patients was high at a community hospital in Taiwan. BMI and FEV 1 were the independent risk factors for osteoporosis in COPD. In addition, COPD patients with osteoporosis had worse HRQL than those without osteoporosis.

Keywords: osteoporosis, chronic obstructive pulmonary disease, bone density

\section{Introduction}

COPD is characterized by persistent airflow limitation caused by an enhanced chronic inflammatory response in the airways and the lungs. ${ }^{1-3}$ It is not only a pulmonary disease but is also being recognized a systemic disease with widespread comorbidities, such as cardiovascular diseases, psychological disorders, and osteoporosis. ${ }^{4-6}$ COPD is the fourth-leading cause of death in the world, and the economic burden related to this disease is projected to increase in coming decades because of continued exposure to COPD risk factors and aging of the general population. ${ }^{7,8}$

Osteoporosis has been recognized as a major comorbidity in COPD, but it is often underdiagnosed and associated with poor health status and prognosis. ${ }^{9}$ The etiology of osteoporosis in COPD is complex, and various risk factors may contribute to its 
pathogenesis, such as older age, tobacco smoking, ${ }^{10}$ systemic inflammation, vitamin D deficiency, and the use of oral or inhaled corticosteroids (ICS). ${ }^{11}$ The reported prevalence of osteoporosis in COPD patients ranges widely from $23 \%$ to $\sim 50 \%$ as diagnosed by bone mineral density (BMD), and from $24 \%$ to $\sim 80 \%$ as diagnosed by BMD or vertebral compression fracture. ${ }^{10,12-20}$ However, there are currently no studies regarding the prevalence and risk factors of osteoporosis in patients with COPD in Taiwan. In addition, few studies have reported an association between health-related quality of life (HRQL) and osteoporosis in patients with COPD. ${ }^{21}$

The primary end point of this study was to investigate the prevalence and risk factors of osteoporosis in COPD among Taiwanese patients. The secondary end point was to examine the association between HRQL and osteoporosis in patients with COPD.

\section{Materials and methods Study setting}

In this cross-sectional study, we examined the data (collected from March 2011 to December 2012) of participants enrolled in the CMPICO study. ${ }^{22}$ In brief, part of the CMPICO study was designed to investigate relevant comorbidities in patients with COPD, such as osteoporosis, cardiovascular diseases, and psychological diseases. The study was carried out at the outpatient department of the Division of Pulmonary and Critical Care Medicine, Ditmanson Medical Foundation, Chia-Yi Christian Hospital, which is a 1,000-bed community-based teaching hospital in Chiayi, Taiwan. The Institutional Review Board of Ditmanson Medical Foundation approved this study (100001), and also approved the consent procedure outlined as follows. The majority of the enrolled individuals provided written informed consent; however, there were a few illiterate subjects enrolled. Our team explained the study design thoroughly to all of these illiterate subjects, and if they agreed to participate, they signed consent forms using fingerprints in lieu of a written signature. A total of 189 COPD patients at outpatient departments were recruited in the CMPICO study during the period, and 125 (66\%) patients were willing to undergo BMD examination and X-ray survey.

\section{Subjects}

A total of 125 COPD patients who had undergone measurement for BMD and spinal X-rays were enrolled in the current study. The diagnosis of COPD was based on the GOLD (Global Initiative for Chronic Obstructive Lung Disease) guidelines. ${ }^{23}$ Eligible patients were $47-90$ years of age with a postbronchodilator forced expiratory volume in 1 second $\left(\mathrm{FEV}_{1}\right)$ to forced vital capacity (FVC) ratio of less than 0.7. ${ }^{19}$ Patients with a history of bronchial asthma and other structural lung diseases (such as lung cancer, bronchiectasis, and fibrotic lung) were excluded. A chest physician carefully reviewed the chest radiographs of all the patients. A total of 125 patients (98\% male) with a mean age of $73.6 \pm 7.69$ years met the inclusion criteria and were enrolled.

\section{Diagnosis of osteoporosis}

BMD was measured by performing a dual-energy X-ray absorptiometry scan of the lumbar spine and bilateral femoral neck. Bone with artificial implantation was excluded in this study. $T$-scores were calculated based on the results of BMD, as described by Brunader and Shelton. ${ }^{24}$ Osteoporosis is defined as a systemic skeletal disease characterized by low-bone density and microarchitectural deterioration of bone tissue, with a consequent increase in bone fragility. ${ }^{25}$ Notably, vertebral fracture has been demonstrated to have a strong relationship with microarchitectural deterioration. ${ }^{26}$ Vertebral fracture was evaluated from a lateral chest X-ray and lumbosacral spine X-ray by an orthopedic surgeon. Fracture was defined as $>20 \%$ reduction in anterior, middle, or posterior height using the semiquantitative method, as described by Genant et al. ${ }^{27}$ As a result, patients with low BMD ( $T$-score $\leq-2.5$ ) or vertebral fracture were diagnosed as having osteoporosis in our study. Otherwise, patients with a $T$-score $>-2.5$ and no vertebral fracture were classified into the nonosteoporosis group (Figure 1).

\section{Health-related quality of life and depression}

Questionnaire tools included the modified Medical Research Council (mMRC) dyspnea scale, ${ }^{28}$ St George's Respiratory Questionnaire (SGRQ), ${ }^{29}$ COPD Assessment Test (CAT), ${ }^{30}$ oxygen-cost diagram (OCD), ${ }^{31}$ and Center for Epidemiologic Studies - depression (CES-D) scale, ${ }^{32}$ and scores were obtained to evaluate each patient's life quality and the severity of depression.

\section{Data collection}

Interviews were conducted by a trained staff member in charge of COPD case management who used a well-established questionnaire to collect demographic information of the study participants, including date of birth, sex, smoking status, and personal medical history. Body weight, height, and blood pressure were measured for each participant. 


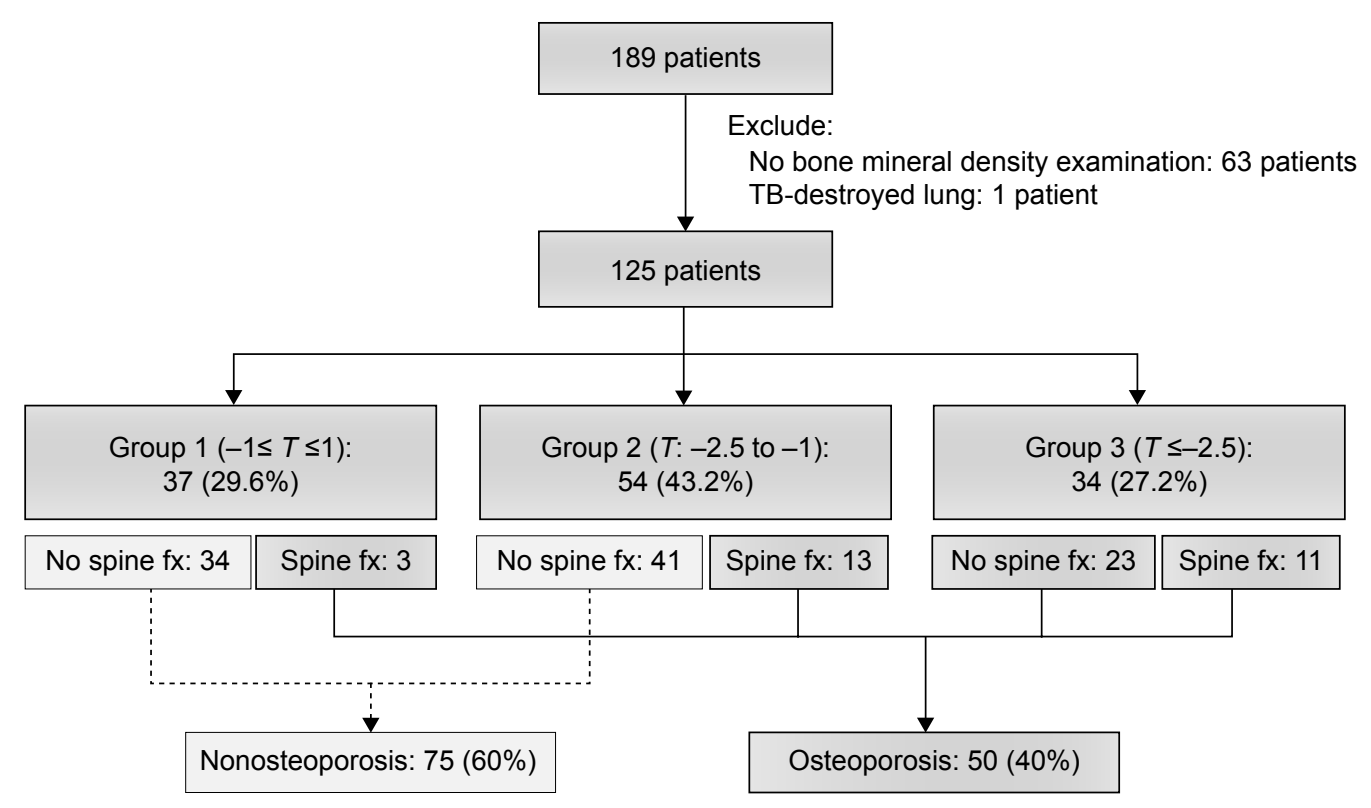

Figure I Algorithm of the study.

Abbreviations: TB, tuberculosis; T, T-score.

Body mass index (BMI) was calculated as weight (kilograms) divided by the square of the height (meters). The subjects self-reported their medical history, including hypertension, hyperlipidemia, and diabetes mellitus, for which the diagnostic definitions are detailed in our previous study. ${ }^{22}$ Smoking status was also evaluated by a self-reported questionnaire.

\section{Statistical analysis}

Data were analyzed by SPSS statistical software for Windows version 22 (IBM Corporation, Armonk, NY, USA). Relationships between two continuous parameters were evaluated by independent Student's $t$-test. Relationships between two discrete parameters were evaluated by cross-table $\chi^{2}$ test. Continuous data are expressed as means \pm standard deviation. Variables with significant difference between the osteoporosis and nonosteoporosis groups were analyzed using a multivariate logistic regression model.

\section{Results}

Of the 125 participants, 50 (40\%) were diagnosed as having osteoporosis. The most common comorbidity observed was hypertension $(n=63,50.4 \%)$, followed by diabetes mellitus $(\mathrm{n}=16,12.8 \%)$, and hyperlipidemia $(\mathrm{n}=13,10.4 \%)$. A total of $118(94.4 \%)$ had a history of smoking (at least 10 packyears), including current $(n=53,42.4 \%)$ and former $(n=65$, $52 \%$ ) smokers. Mean pack-years of smoking was 47.22.

As shown in Table 1, there were no significant differences in clinical characteristics between the COPD patients with and without osteoporosis with the exception of BMI, which showed that COPD patients with osteoporosis had a lower BMI than patients without osteoporosis $(21.75 \pm 3.4$ vs 23.93 $\pm 3.3, P=0.001)$. Certainly, COPD patients with osteoporosis had lower values with regard to the parameters of lumbar spine, left femoral neck, right femoral neck, and $T$-score in terms of BMD than COPD patients without osteoporosis.

Severity of COPD had been classified in stages (I-IV) previously and groups (A-D) currently according to the GOLD guidelines. Comparing the GOLD stages (I-IV) between the COPD patients with and without osteoporosis, there was no significant difference between the two groups. However, if patients were classified by current GOLD groups $(A-D)$, there was a significant difference between the two groups $(P=0.024$, Table 2$)$. However, COPD patients with osteoporosis had significantly lower $\mathrm{FEV}_{1}(1.07 \pm 0.37$ vs $1.28 \pm 0.45 \mathrm{~L}, P=0.007)$, and $\mathrm{FEV}_{1} / \mathrm{FVC}$ $(52.79 \pm 11.0$ vs $58.43 \pm 8.9, P=0.002)$ than those without osteoporosis.

Using a multivariate logistic regression model that included age, smoking amount (pack-year), BMI, and FEV ${ }_{1}$, only BMI (odds ratio [OR] 0.824, 95\% confidence interval $0.73-0.93 ; P=0.002)$ and $\mathrm{FEV}_{1}(\mathrm{OR} 0.360,95 \%$ confidence interval $0.13-0.98 ; P=0.046$ ) were significantly associated with an increased risk of osteoporosis in COPD patients (Table 3).

To evaluate the HRQL in all enrolled patients, various questionnaires were obtained and analyzed (Table 4). COPD patients with osteoporosis had significantly higher mMRC 
Table I Clinical characteristics of COPD patient with and without osteoporosis

\begin{tabular}{|c|c|c|c|}
\hline & $\begin{array}{l}\text { Nonosteoporosis } \\
n=75\end{array}$ & $\begin{array}{l}\text { Osteoporosis } \\
n=50\end{array}$ & $P$-value \\
\hline Age, years, mean \pm SD & $71.7 \pm 7.2$ & $73.6 \pm 7.7$ & 0.173 \\
\hline Sex, male, n (\%) & $74(98.7)$ & $49(98.0)$ & 1.000 \\
\hline $\mathrm{BMl}, \mathrm{kg} / \mathrm{m}^{2}$, mean $\pm \mathrm{SD}$ & $23.9 \pm 3.3$ & $21.8 \pm 3.4$ & 0.001 \\
\hline \multicolumn{4}{|l|}{ Smoking, n (\%) } \\
\hline Never & $3(4.0)$ & $4(8.0)$ & 0.414 \\
\hline Quit & $37(49.3)$ & $28(56.0)$ & \\
\hline Current & $35(46.7)$ & $18(36.0)$ & \\
\hline Smoking amount, pack-years, mean \pm SD & $45.8 \pm 27.0$ & $49.4 \pm 30.6$ & 0.490 \\
\hline \multicolumn{4}{|l|}{$B M D$, mean $\pm S D$} \\
\hline LS & $I . I I \pm 0.14$ & $0.905 \pm 0.159$ & $<0.001$ \\
\hline LFK & $0.86 \pm 0.17$ & $0.682 \pm 0.120$ & $<0.001$ \\
\hline RFK & $0.87 \pm 0.16$ & $0.689 \pm 0.121$ & $<0.001$ \\
\hline$T$-score & $-1.169 \pm 0.81$ & $-2.48 \pm 0.89$ & $<0.001$ \\
\hline \multicolumn{4}{|l|}{ Underlying disease, n (\%) } \\
\hline DM & $10(13.3)$ & $6(12)$ & 0.827 \\
\hline HTN & $43(57.3)$ & $20(40)$ & 0.058 \\
\hline Hyperlipidemia & II (I4.7) & $2(4)$ & 0.074 \\
\hline Alcohol & $24(32)$ & $9(18)$ & 0.082 \\
\hline CAD & $3(4)$ & $4(8)$ & 0.436 \\
\hline $\mathrm{CHF}$ & $2(2.7)$ & $6(12)$ & 0.059 \\
\hline CKD & $5(6.7)$ & I (2) & 0.400 \\
\hline CLD & $9(12)$ & $2(4)$ & 0.197 \\
\hline Education, n (\%) & & & 0.612 \\
\hline Illiterate & I7 (22.7) & II (22) & \\
\hline Elementary & $33(44)$ & $29(58)$ & \\
\hline Junior & $5(6.7)$ & $3(6)$ & \\
\hline Senior & II (I4.7) & $5(10)$ & \\
\hline College & $7(9.3)$ & $2(4)$ & \\
\hline
\end{tabular}

Note: Education represents the highest academic degree of patient.

Abbreviations: BMI, body mass index; BMD, body mineral density; CAD, coronary artery disease; CHF, congestive heart failure; CKD, chronic kidney disease mellitus; CLD, chronic liver disease; DM, diabetes mellitus; HTN, hypertension; LFK, left femoral neck; LS, lumbar spine; RFK, right femoral neck; SD, standard deviation.

scores $(1.7 \pm 0.8$ vs $1.4 \pm 0.8, P=0.046)$, higher SGRQ scores (36.6 vs 28.0, $P=0.01$ ), lower OCD scores (4.8 \pm 1.8 vs $5.4 \pm 1.6, P=0.045)$, and higher CAT scores $(14.7 \pm 8$ vs $11.5 \pm 7$, $P=0.019)$ than patients without osteoporosis. However, there was no significant difference in CES-D scores between the two groups.

\section{Discussion}

To the best of our knowledge, this is the first study to highlight the prevalence and risk factors of osteoporosis in patients with COPD at a community hospital in Taiwan. Our study showed that the prevalence of osteoporosis was $40 \%$ in patients with COPD. COPD patients with osteoporosis had lower BMI, $\mathrm{FEV}_{1}$, and $\mathrm{FEV}_{1} / \mathrm{FVC}$ than COPD patients without osteoporosis. In a multivariate logistic regression model, only $\mathrm{BMI}$ and $\mathrm{FEV}_{1}$ were significantly associated with an increased risk of osteoporosis in COPD patients. When comparing the HRQL between the two groups, COPD patients with osteoporosis had significantly higher mMRC scores, SGRQ scores, CAT scores, and lower OCD scores than those without osteoporosis, indicating that osteoporosis patients had worse quality of life and exercise performance.

Osteoporosis has been recognized as an emerging issue in the care of COPD, since osteoporosis would increase the difficulty and complexity in the management of COPD. It has also been identified as most at risk for the experiencing of severe exacerbations requiring hospitalization. ${ }^{33}$ As shown in Table 5, there have been a number of studies investigating the prevalence and related risk factors worldwide over the past decade. ${ }^{12,15,17-20}$ Based on different definitions, the prevalence of osteoporosis ranges from $23 \%$ to $42 \%$ diagnosed only by BMD and from $47 \%$ to $83.7 \%$ diagnosed by both BMD and vertebral compression fracture. ${ }^{12,17-20}$ The wide range with regard to osteoporosis-prevalence rates in the world may be in part be related to the methodological differences of 
Table 2 GOLD stage and pulmonary function in COPD patients with and without osteoporosis

\begin{tabular}{|c|c|c|c|}
\hline & $\begin{array}{l}\text { Nonosteoporosis } \\
n=75\end{array}$ & $\begin{array}{l}\text { Osteoporosis } \\
n=50\end{array}$ & $P$-value \\
\hline GOLD, n (\%) & & & 0.255 \\
\hline Stage I & $8(\mathrm{II})$ & $5(10)$ & \\
\hline Stage II & $40(53)$ & $19(38)$ & \\
\hline Stage III & $24(32)$ & $21(42)$ & \\
\hline Stage IV & $3(4)$ & $5(10)$ & \\
\hline GOLD, n (\%) & & & 0.024 \\
\hline Group A & $30(40)$ & $13(26)$ & \\
\hline Group B & $12(16)$ & $8(16)$ & \\
\hline Group C & $17(22.7)$ & $6(12)$ & \\
\hline Group D & $16(21)$ & $23(46)$ & \\
\hline Systolic BP, mmHg, mean \pm SD & $137 \pm 16$ & $133 \pm 16$ & 0.155 \\
\hline Diastolic BP $(\mathrm{mmHg})$, mean $\pm \mathrm{SD}$ & $82 \pm 12$ & $79 \pm 12$ & 0.283 \\
\hline Heart rate/minute, mean \pm SD & $84 \pm 15$ & $84 \pm 15$ & 0.850 \\
\hline $\mathrm{SpO}_{2}, \%$, mean $\pm \mathrm{SD}$ & $95 \pm 2$ & $95 \pm 3$ & 0.212 \\
\hline \multicolumn{4}{|l|}{ Pulmonary function } \\
\hline FVC, liters, mean \pm SD & $2.15 \pm 0.59$ & $1.99 \pm 0.45$ & 0.111 \\
\hline FVC, predicted $\%$, mean \pm SD & $63.6 \pm 17$ & $58.7 \pm 14$ & 0.096 \\
\hline $\mathrm{FEV}_{1}$, liters, mean $\pm \mathrm{SD}$ & $1.28 \pm 0.45$ & $1.07 \pm 0.37$ & 0.007 \\
\hline $\mathrm{FEV}_{1}$, predicted $\%$, mean $\pm \mathrm{SD}$ & $58.4 \pm 18$ & $48.5 \pm 19$ & 0.080 \\
\hline $\mathrm{FEV}_{1} / \mathrm{FVC}$, mean $\pm \mathrm{SD}$ & $58.43 \pm 8.9$ & $52.79 \pm 11.0$ & 0.002 \\
\hline BD response, $n(\%)$ & $13(17.3)$ & $9(18)$ & 0.924 \\
\hline MMEF, liters, mean \pm SD & $0.66 \pm 0.38$ & $1.61 \pm 7.86$ & 0.399 \\
\hline
\end{tabular}

Abbreviations: GOLD, Global Initiative for Chronic Obstructive Lung Disease; BP, blood pressure; SD, standard deviation; SpO ${ }_{2}$, oximetric oxygen saturation; FVC, forced vital capacity; $\mathrm{FEV}_{1}$, forced expiratory volume in I second; BD, bronchodilator; MMEF, maximum midexpiratory flow.

osteoporosis diagnosis and the enrollment criteria of patient populations, such as age and severity of COPD.

Malnutrition, indicated by lower BMI, is a possible cause of bone loss and fractures, frequently associated with inflammation and hormonal change. ${ }^{34}$ Several studies have confirmed that $\mathrm{BMI}$ is positively associated with $\mathrm{BMD}$ in a variety of patient populations. ${ }^{35-38}$ Not surprisingly, this is consistent in patients with COPD based on previous studies ${ }^{12,13,15,16,19}$ and also as seen in our findings, which all showed that BMI was an independent risk factor for osteoporosis.

Similarly to previous reports, , $2,13,15,16,19$ our data showed that pulmonary function, like $\mathrm{FEV}_{1}$ or $\mathrm{FVC}$, was the independent risk factor for osteoporosis. A South Korean study that enrolled 456 premenopausal women who had never smoked showed that $\mathrm{FVC}$ and $\mathrm{FEV}_{1}$ were correlated with
BMD. ${ }^{39}$ This is consistent with our findings showing that $\mathrm{FEV}_{1}$ is an independent risk factor regardless of smoking history.

The related literature has been inconsistent as to whether oral steroid use is a risk factor for osteoporosis in COPD. ${ }^{13,15,17,40}$ The TORCH study demonstrated that ICS use was not associated with BMD ${ }^{18}$ Other studies likewise have shown that oral steroid use was not correlated with osteoporosis in patients with COPD. ${ }^{15,17}$ On the contrary, ICS use was associated with a modest but statistically significant increase $(>20 \%)$ in the risk of fractures in patients with COPD from a meta-analysis of randomized controlled trials (16 trials) and observational studies (seven trials). ${ }^{41}$ Another large case-control study showed that current use of high-dose ICS (more than $700 \mu \mathrm{g} /$ day) was associated with an increased

Table 3 Multivariate logistic regression analysis of factors for osteoporosis in COPD patients

\begin{tabular}{|c|c|c|c|c|c|c|}
\hline \multirow[t]{2}{*}{ Variables } & \multirow[t]{2}{*}{ B } & \multirow[t]{2}{*}{ SE } & \multirow{2}{*}{$\begin{array}{l}\text { Odds } \\
\text { ratio }\end{array}$} & \multicolumn{2}{|c|}{$95 \% \mathrm{Cl}$ for Odds ratio } & \multirow[t]{2}{*}{$P$-value } \\
\hline & & & & Lower & Upper & \\
\hline Smoking amount (pack-years) & 0.008 & 0.007 & 1.008 & 0.995 & 1.022 & 0.229 \\
\hline Age (years) & 0.020 & 0.028 & 1.020 & 0.965 & 1.078 & 0.476 \\
\hline BMI $\left(\mathrm{kg} / \mathrm{m}^{2}\right)$ & -0.194 & 0.064 & 0.824 & 0.727 & 0.933 & 0.002 \\
\hline $\mathrm{FEV}_{1}(\mathrm{~L} / \mathrm{s})$ & -1.021 & 0.511 & 0.360 & 0.132 & $0.98 \mathrm{I}$ & 0.046 \\
\hline Constant & 3.332 & 2.679 & 27.988 & & & 0.214 \\
\hline
\end{tabular}

Abbreviations: $\mathrm{Cl}$, confidence interval; $\mathrm{SE}$, standard error; $\mathrm{BMI}$, body mass index; $\mathrm{FEV}$, forced expiratory volume in I second. 
Table 4 Health-related quality of life in COPD patients with and without osteoporosis

\begin{tabular}{|c|c|c|c|}
\hline & $\begin{array}{l}\text { Nonosteoporosis } \\
n=75\end{array}$ & $\begin{array}{l}\text { Osteoporosis } \\
n=50\end{array}$ & $P$-value \\
\hline $\mathrm{mMRC}$, mean $\pm \mathrm{SD}$ & $1.4 \pm 0.8$ & $1.7 \pm 0.8$ & 0.046 \\
\hline mMRC grades & & & 0.156 \\
\hline Grade 0, n (\%) & $5(7)$ & $2(4)$ & \\
\hline Grade I, n (\%) & $42(56)$ & $18(38)$ & \\
\hline Grade 2, n (\%) & $22(29)$ & $21(44)$ & \\
\hline Grade 3, n (\%) & $5(7)$ & $7(15)$ & \\
\hline Grade 4, n (\%) & $\mathrm{I}(\mathrm{I})$ & 0 & \\
\hline $\mathrm{mMRC} \geq 2, \mathrm{n}(\%)$ & $28(37.3)$ & $28(56)$ & 0.045 \\
\hline SGRQ, mean $\pm S D$ & $28.0 \pm 17.3$ & $36.6 \pm 18.6$ & 0.010 \\
\hline$O C D$, mean $\pm S D$ & $5.4 \pm 1.6$ & $4.8 \pm 1.8$ & 0.045 \\
\hline CES-D, mean $\pm S D$ & $11.7 \pm 8.0$ & $13.6 \pm 8.6$ & 0.434 \\
\hline $\mathrm{CAT}$, mean $\pm \mathrm{SD}$ & $11.5 \pm 7$ & $14.7 \pm 8$ & 0.019 \\
\hline
\end{tabular}

Notes: Two mMRC score data and one CES-D score data in osteoporosis patients were missing.

Abbreviations: mMRC, modified Medical Research Council; SD, standard deviation; SGRQ, St George's Respiratory Questionnaire; OCD, oxygen-cost diagram; CES-D, Center for Epidemiologic Studies - depression; CAT, COPD Assessment Test.

risk of nonvertebral fractures compared with patients with no ICS exposure (adjusted OR 1.68). Therefore, the impact of ICS should be further verified by studies in the future.

A study reported on an association between HRQL and osteoporosis in patients with COPD. ${ }^{21}$ This study showed that HRQL, which was assessed by mMRC scale, SGRQ, and CAT scores, was significantly worse in patients with osteoporosis than those without osteoporosis. The mMRC scale is based on the patient's perception of dyspnea in daily activities, ${ }^{28}$ and is a practical tool to assess the HRQL of patients with COPD. ${ }^{42}$ Notably, current GOLD guidelines combine a dyspnea scale (mMRC or CAT) and pulmonary function to classify the severity of COPD, which is compatible with our finding that the proportion of osteoporosis was more correlated with group classification than stage classification (pulmonary function alone). This study showed that osteoporosis was associated with higher mMRC dyspnea scores in patients with COPD, which is similar with results from previous studies. ${ }^{43,44}$ There is a paucity of data regarding the association between SGRQ and osteoporosis. To the best of our knowledge, this is the first study revealing that COPD patients with osteoporosis had higher SGRQ scores than those without osteoporosis. The CES-D scale is a short self-reporting scale designed to measure depressive symptomatology in the general population. This study showed that depression was not associated with osteoporosis in patients with COPD.

This study has a number of limitations that are worth noting. First, the sample size was small, and the majority of patients were male. A previous study has shown that the ratio of male to female smoking rates was 10.9 to 1 among adults in Taiwan. ${ }^{9}$ Since smoking is the major risk factor for COPD, it is reasonable that COPD patients are predominantly male in Taiwan. However, large studies are needed to verify our results. Second, information regarding possible risk factors

Table 5 Prevalence and related risk factors of osteoporosis in COPD patients for the past decade worldwide

\begin{tabular}{|c|c|c|c|c|}
\hline Study & Country & $\mathbf{n}$ & Osteoporosis (\%) & Associated factors \\
\hline Watanabe et al ${ }^{12}$ & Japan & 136 & $\begin{array}{l}38.8 \% \text { by } \mathrm{BMD}^{\mathrm{a}}, 79.4 \% \text { by } \mathrm{VCF} \\
83.7 \% \text { by } \mathrm{BMD} \text { and } \mathrm{VCF}^{\mathrm{b}}\end{array}$ & $(+):$ FEV $_{1}$, FVC, smoking \\
\hline Hattiholi and Gaude ${ }^{13}$ & India & 102 & $66.6 \%$ by BMD & $(+)$ : COPD stage, low BMI, AEs $>3$, steroids \\
\hline Li et al ${ }^{14}$ & USA & 179 & $\begin{array}{l}69 \% \text { in African-Americans } \\
65 \% \text { in Caucasians by BMD }\end{array}$ & $\begin{array}{l}\text { (+): FVC/predicted FVC } \\
(-): \text { Sex, race }\end{array}$ \\
\hline Silva et al ${ }^{15}$ & Brazil & 95 & $42.1 \%$ by $\mathrm{BMD}$ & $\begin{array}{l}\text { (+): Low BMI, activity, BODE, FVC, FRV, IC, } \\
D_{\text {LCO }} \\
(-) \text { : Oral steroids, smoking, } 6 \mathrm{MWT}\end{array}$ \\
\hline Rittayamai et al ${ }^{16}$ & Thailand & 102 & $31.4 \%$ by $\mathrm{BMD}$ & $\begin{array}{l}(+): \text { BMI }<20.5 \mathrm{~kg} / \mathrm{m}^{2} \text { and } \mathrm{hs}-\mathrm{CRP}>2.3 \mathrm{mg} / \mathrm{L} \\
(-): \text { COPD stage, age, smoking, and steroid use }\end{array}$ \\
\hline Jørgensen et al ${ }^{17}$ & Denmark & 62 & $\begin{array}{l}24 \% \text { by VCF } \\
42 \% \text { by BMD }\end{array}$ & $(-)$ : Steroids, FEV , FVC, smoking \\
\hline Ferguson et al ${ }^{18} \mathrm{TORCH}$ & & 658 & $23 \%$ by $\mathrm{BMD}$ & $(-)$ : ICS, fluticasone \\
\hline Graat-Verboom et al ${ }^{19}$ & the Netherlands & 49 & $\begin{array}{l}50 \% \text { in GOLD-II } \\
\text { by } \mathrm{BMD} \text { and } \mathrm{VCF}^{\mathrm{b}}\end{array}$ & (+): Low BMI, high RV/TLC \\
\hline Graat-Verboom et $\mathrm{al}^{20}$ & the Netherlands & 90 & $\begin{array}{l}47 \%-61 \% \text { in } 3 \text { years } \\
\text { by } B M D \text { and } V C F^{b}\end{array}$ & $\begin{array}{l}(+) \text { : Low } T \text {-score in trochanter, vitamin D } \\
\text { deficiency } \\
(-) \text { : Smoking }\end{array}$ \\
\hline
\end{tabular}

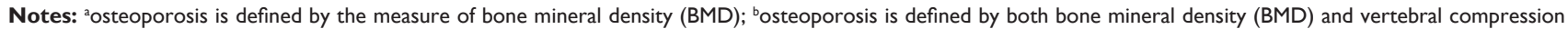
fracture (VCF). (+) A significant risk factor for osteoporosis and (-) not a significant risk factor for osteoporosis.

Abbreviations: BMD, bone mineral density; VCF, vertebral compression fracture; FEV , forced expiratory volume in I second; FVC, forced vital capacity; BMI, body mass index; AEs, acute exacerbation; BODE, BMI, obstruction (airflow), dyspnea (score), exercise (capacity); FRV, functional residual volume; IC, inspiratory capacity; $\mathrm{D}_{\text {Lco, }}$ diffusing capacity of the lungs for carbon monoxide; 6MWT, 6-minute walking test; hs-CRP, highly sensitive C-reactive protein; ICS, inhaled corticosteroids; TORCH, Towards a Revolution in COPD Health; GOLD, Global Initiative of Chronic Obstructive Lung Disease; TLC, total lung capacity. 
like vitamin D deficiency and oral steroid use was unavailable during our study. However, most previous studies showed that oral steroids were not associated with increased risk of osteoporosis in patients with COPD.

In conclusion, the prevalence of osteoporosis in COPD patients was high in Taiwan. BMI and $\mathrm{FEV}_{1}$ were the independent risk factors for osteoporosis in COPD. Therefore, measuring BMD in COPD patients with lower BMI or pulmonary function should be recommended. As a result, further study may be required to investigate whether the prevention of osteoporosis utilizing such strategies as increasing body weight, encouraging smoke cessation, and/or prescribing medications that can help prevent osteoporosis would improve the quality of life in patients with COPD.

\section{Disclosure}

The authors report no conflicts of interest in this work.

\section{References}

1. Hogg JC, Chu F, Utokaparch S, et al. The nature of small-airway obstruction in chronic obstructive pulmonary disease. $N$ Engl $J$ Med. 2004;350(26):2645-2653.

2. Tamimi A, Serdarevic D, Hanania NA. The effects of cigarette smoke on airway inflammation in asthma and COPD: therapeutic implications. Respir Med. 2012;106(3):319-328.

3. Garcia-Rio F, Miravitlles M, Soriano JB, et al. Systemic inflammation in chronic obstructive pulmonary disease: a population-based study. Respir Res. 2010;11:63.

4. Fabbri LM, Luppi F, Beghé B, Rabe KF. Complex chronic comorbidities of COPD. Eur Respir J. 2008;31(1):204-212.

5. Soriano JB, Visick GT, Muellerova H, Payvandi N, Hansell AL. Patterns of comorbidities in newly diagnosed COPD and asthma in primary care. Chest. 2005;128(4):2099-2107.

6. Decramer M, Janssens W, Miravitlles M. Chronic obstructive pulmonary disease. Lancet. 2012;379(9823):1341-1351.

7. Fletcher MJ, Upton J, Taylor-Fishwick J, et al. COPD uncovered: an international survey on the impact of chronic obstructive pulmonary disease [COPD] on a working age population. BMC Public Health. 2011;11:612

8. Mannino DM, Kiriz VA. Changing the burden of COPD mortality. Int J Chron Obstruct Pulmon Dis. 2006;1(3):219-233.

9. Wen CP, Levy DT, Cheng TY, Hsu CC, Tsai SP. Smoking behaviour in Taiwan, 2001. Tob Control. 2005;14 Suppl 1:i51-i55.

10. Vrieze A, de Greef MH, Wijkstra PJ, Wempe JB. Low bone mineral density in COPD patients related to worse lung function, low weight and decreased fat-free mass. Osteoporos Int. 2007;18(9): 1197-1202.

11. Romme EA, Smeenk FW, Rutten EP, Wouters EF. Osteoporosis in chronic obstructive pulmonary disease. Expert Rev Respir Med. 2013; 7(4):397-410.

12. Watanabe R, Tanaka T, Aita K, et al. Osteoporosis is highly prevalent in Japanese males with chronic obstructive pulmonary disease and is associated with deteriorated pulmonary function. J Bone Miner Metab. Epub 2014 Jul 5.

13. Hattiholi J, Gaude GS. Prevalence and correlates of osteoporosis in chronic obstructive pulmonary disease patients in India. Lung India. 2014;31(3):221-227.

14. Li L, Brennan KJ, Gaughan JP, Ciccolella DE, Kuzma AM, Criner GJ. African Americans and men with severe COPD have a high prevalence of osteoporosis. COPD. 2008;5(5):291-297.
15. Silva DR, Coelho AC, Dumke A, et al. Osteoporosis prevalence and associated factors in patients with COPD: a cross-sectional study. Respir Care. 2011;56(7):961-968.

16. Rittayamai N, Chuaychoo B, Sriwijitkamol A. Prevalence of osteoporosis and osteopenia in Thai COPD patients. J Med Assoc Thai. 2012; 95(8):1021-1027.

17. Jørgensen NR, Schwarz P, Holme I, Henriksen BM, Petersen LJ, Backer $\mathrm{V}$. The prevalence of osteoporosis in patients with chronic obstructive pulmonary disease: a cross sectional study. Respir Med. 2007; 101(1):177-185.

18. Ferguson GT, Calverley PM, Anderson JA, et al. Prevalence and progression of osteoporosis in patients with COPD: results from the TOwards a Revolution in COPD Health study. Chest. 2009;136(6):1456-1465.

19. Graat-Verboom L, Smeenk FW, van den Borne BE, et al. Risk factors for osteoporosis in Caucasian patients with moderate chronic obstructive pulmonary disease: a case control study. Bone. 2012;50(6): 1234-1239.

20. Graat-Verboom L, Smeenk FW, van den Borne BE, et al. Progression of osteoporosis in patients with COPD: a 3-year follow up study. Respir Med. 2012;106(6):861-870.

21. Sundh J, Johansson G, Larsson K, et al. Comorbidity and health-related quality of life in patients with severe chronic obstructive pulmonary disease attending Swedish secondary care units. Int J Chron Obstruct Pulmon Dis. 2015;10:173-183.

22. Lin MS, Hsu KY, Chen YJ, Chen CR, Chen CM, Chen W. Prevalence and risk factors of asymptomatic peripheral arterial disease in patients with COPD in Taiwan. PLoS One. 2013;8(5):e64714.

23. Johannessen A, Nilsen RM, Storebø M, Gulsvik A, Eagan T, Bakke P. Comparison of 2011 and 2007 Global Initiative for Chronic Obstructive Lung Disease guidelines for predicting mortality and hospitalization. Am J Respir Crit Care Med. 2013;188(1):51-59.

24. Brunader R, Shelton DK. Radiologic bone assessment in the evaluation of osteoporosis. Am Fam Physician. 2002;65(7):1357-1364.

25. Le Gall JR, Lemeshow S, Saulnier F. A new Simplified Acute Physiology Score (SAPS II) based on a European/North American multicenter study. JAMA. 1993;270(24):2957-2963.

26. Genant HK, Delmas PD, Chen P, et al. Severity of vertebral fracture reflects deterioration of bone microarchitecture. Osteoporos Int. 2007; 18(1):69-76.

27. Genant $\mathrm{HK}, \mathrm{Wu} \mathrm{CY}$, van Kuijk C, Nevitt MC. Vertebral fracture assessment using a semiquantitative technique. J Bone Miner Res. 1993; 8(9):1137-1148

28. Mahler DA, Wells CK. Evaluation of clinical methods for rating dyspnea. Chest. 1988;93(3):580-586.

29. Jones PW, Quirk FH, Baveystock CM, Littlejohns P. A self-complete measure of health status for chronic airflow limitation. The St George's Respiratory Questionnaire. Am Rev Respir Dis. 1992; 145(6):1321-1327.

30. Jones PW, Harding G, Berry P, Wiklund I, Chen WH, Kline Leidy N. Development and first validation of the COPD Assessment Test. Eur Respir J. 2009;34(3):648-654.

31. Mahler DA, Harver A. A factor analysis of dyspnea ratings, respiratory muscle strength, and lung function in patients with chronic obstructive pulmonary disease. Am Rev Respir Dis. 1992;145(2 Pt 1):467-470.

32. van Manen JG, Bindels PJ, Dekker FW, IJzermans CJ, van der Zee JS, Schadé E. Risk of depression in patients with chronic obstructive pulmonary disease and its determinants. Thorax. 2002;57(5):412-416.

33. McGarvey L, Lee AJ, Roberts J, Gruffydd-Jones K, McKnight E, Haughney J. Characterisation of the frequent exacerbator phenotype in COPD patients in a large UK primary care population. Respir Med. 2015;109(2):228-237.

34. Montalcini T, Romeo S, Ferro Y, Migliaccio V, Gazzaruso C, Pujia A. Osteoporosis in chronic inflammatory disease: the role of malnutrition. Endocrine. 2013;43(1):59-64.

35. Lloyd JT, Alley DE, Hawkes WG, Hochberg MC, Waldstein SR, Orwig DL. Body mass index is positively associated with bone mineral density in US older adults. Arch Osteoporos. 2014;9(1):175. 
36. Hoxha R, Islami H, Qorraj-Bytyqi H, Thaçi S, Bahtiri E. Relationship of weight and body mass index with bone mineral density in adult men from Kosovo. Mater Sociomed. 2014;26(5):306-308.

37. Nagi R, Devi BK, Rakesh N, Reddy SS, Santana N, Shetty N. Relationship between femur bone mineral density, body mass index and dental panoramic mandibular cortical width in diagnosis of elderly postmenopausal women with osteoporosis. J Clin Diagn Res. 2014; 8(8):ZC36-ZC40.

38. Pinnetti $\mathrm{C}$, et al. Relationship between body mass index and bone mineral density in HIV-infected patients referred for DXA. J Int AIDS Soc. 2014;17(4 Suppl 3):19569.

39. Jeon YK, Shin MJ, Kim WJ, et al. The relationship between pulmonary function and bone mineral density in healthy nonsmoking women: the Korean National Health and Nutrition Examination Survey (KNHANES) 2010. Osteoporos Int. 2014;25(5):1571-1576.

40. Grossman JM, Gordon R, Ranganath VK, et al. American College of Rheumatology 2010 recommendations for the prevention and treatment of glucocorticoid-induced osteoporosis. Arthritis Care Res (Hoboken). 2010;62(11):1515-1526.
41. Loke YK, Cavallazzi R, Singh S. Risk of fractures with inhaled corticosteroids in COPD: systematic review and meta-analysis of randomised controlled trials and observational studies. Thorax. 2011;66(8):699-708.

42. Hsu KY, Lin JR, Lin MS, Chen W, Chen YJ, Yan YH. The modified Medical Research Council dyspnoea scale is a good indicator of healthrelated quality of life in patients with chronic obstructive pulmonary disease. Singapore Med J. 2013;54(6):321-327.

43. Miller J, Edwards LD, Agustí A, et al. Comorbidity, systemic inflammation and outcomes in the ECLIPSE cohort. Respir Med. 2013; 107(9):1376-1384

44. Sin DD, Man JP, Man SF. The risk of osteoporosis in Caucasian men and women with obstructive airways disease. Am J Med. 2003; 114(1):10-14.

\section{Publish your work in this journal}

The International Journal of COPD is an international, peer-reviewed journal of therapeutics and pharmacology focusing on concise rapid reporting of clinical studies and reviews in COPD. Special focus is given to the pathophysiological processes underlying the disease, intervention programs, patient focused education, and self management protocols.

\section{Dovepress}

This journal is indexed on PubMed Central, MedLine and CAS. The manuscript management system is completely online and includes a very quick and fair peer-review system, which is all easy to use. Visit $\mathrm{http} / / / \mathrm{www}$.dovepress.com/testimonials.php to read real quotes from published authors. 